\title{
AC 2009-919: SELF-ORGANIZING UNITS TO PROMOTE INTERDISCIPLINARY TEAMING IN A COURSE FOR PERVASIVE COMPUTING DESIGN
}

\section{Lisa McNair, Virginia Tech}

Lisa McNair is an Assistant Professor in the Department of Engineering Education at Virginia Tech, where she co-directs the Virginia Tech Engineering Communications Center. She received her Ph.D. in Linguistics from the University of Chicago in 2002. Her research explores collaboration in interdisciplinary and distributed settings, and institutional structures that encourage transformational learning.

\section{Chad Newswander, Virginia Tech}

Chad Newswander is a graduate student in the Center for Public Administration and Policy at Virginia Tech, studying interdisciplinary design teams with Drs. Lisa McNair and Marie Paretti.

\section{Eloise Coupey, Virginia Tech}

Eloise Coupey is an Associate Professor of Marketing in the Pamplin College of Business at Virginia Tech. She received her PhD in Business Administration from Duke University in 1990, and a BA degree from Harvard University in 1983. She researches consumer and managerial decision making, and the nature and influence of information technologies on decision aspects related to the adoption of products and ideas.

\section{Ed Dorsa, Virginia Tech}

Ed Dorsa is an Associate Professor of Industrial Design in the College of Architecture and Urban Studies at Virginia Tech. He received his Master and Bachelor of Industrial Design from the Ohio State University. He is the past Vice President of Education for the Industrial Designers Society of America and has chaired the past two National Education Symposia for IDSA. He presently serves as a Commissioner for Accreditation for the National Association of Schools of Art and Design.

\section{Tom Martin, Virginia Tech}

Tom Martin is an associate professor in the Bradley Department of Electrical and Computer Engineering at Virginia Tech. He received his Ph.D. in Electrical and Computer Engineering from Carnegie Mellon University in 1999 and his BS in Electrical Engineering from the University of Cincinnati in 1992. Martin is on the steering committee for IEEE Technical Committee for Wearable Information Systems and has served as general chair and program co-chair of the IEEE Computer Society's International Symposium on Wearable Computers.

\section{Marie Paretti, Virginia Tech}

Marie C. Paretti is an assistant professor of Engineering Education at Virginia Tech, where she co-directs the Virginia Tech Engineering Communications Center. Her research focuses on communication in engineering design, interdisciplinary communication and collaboration, and design education. She was awarded a CAREER grant from NSF to study expert teaching practices in capstone design courses nationwide, and is co-PI on several NSF grants to explore interdisciplinary collaboration in engineering design. 


\title{
Self-Organizing Units in an Interdisciplinary Course for Pervasive Computing Design
}

\begin{abstract}
We conducted a case study of a design course that focused on bringing together students from engineering, industrial design, and marketing to use pervasive computing technologies to design, coordinate, and build a "smart" dorm room for disabled individuals. The class was loosely structured to encourage innovation, critical thinking and interdisciplinarity. In this environment, teams were created, disassembled, and re-created in a self-organizing fashion. With few norms, teams were expected to be interdisciplinary, form quickly, and work together by creatively integrating their disciplinary expertise.

In observing this semester-long class, we found certain conditions that will enhance pedagogical tools designed to expedite team formation and improve collaborative practices in a classroom setting. Similar to open source software development, we found that groups can form randomly in a loosely coordinated environment that is both self-managing and self-directing if instructors create a strong normative foundation to the class. In this case study, we observed that the applied concept of self-organizing buffered with strong faculty input invests group members with a greater commitment to be productive, effective, and innovative.
\end{abstract}

Keywords: interdisciplinary collaboration, group formation, self-organizing units

\section{Introduction}

Work teams are often led by project managers and situated in a large organizational environment where routine and predictability are valued. In certain settings, such as in open source software development, ${ }^{1}$ groups can form without traditional project management structure in a loosely coordinated environment that is both self-organizing and self-managing. This concept of selforganizing invests group members with a greater commitment to be productive, effective, and innovative. However, there has still been little discussion about self-organizing teams in an educational setting. By breaking down disciplinary divisions to create a well-functioning unit that is coordinated and interdependent, the authors conducted a case study of how instructors can help students replicate emerging industry practices by encouraging students to self-organize teams in an interdisciplinary context that includes engineering, industrial design, and marketing.

The case study focused on a course that brought students from a variety of disciplines together to use pervasive computing technologies to design, coordinate, and build components for a "smart" dorm room for disabled individuals. These intelligent components are intended to transparently interact with users. Examples of projects that the students worked on included a modular furniture system with a survey-based selection system, a social-networking "hive" to help students more easily integrate into the dorm and campus community, an interactive mirror to provide reminders and help with grooming activities, a personal assistant robot to fetch small items and help navigate campus, and a bracelet to provide emergency information, replace door keys, and act as a digital wallet. 
In the course, interdisciplinary teams were created, disassembled, and re-created in a selforganizing fashion. With few but very strong norms, teams were encouraged to be interdisciplinary, form quickly, and work together by initially "checking their disciplines at the door" and concentrating on ideation and synergy. The construction of teams with members from different disciplines and backgrounds is necessary for pervasive computing design. We postulate that individuals are more engaged in groups that form randomly in a loosely coordinated environment that is both self-organizing and self-managing.

The research questions guiding our inquiry are:

1. What instructor strategies help to create an interdisciplinary environment that facilitates quick formation of cohesive teams?

2. How do self-organized and self-managed teaming impact individuals' engagement in teaming and design?

The results of this research describe pedagogical approaches that can be used to help expedite and facilitate team formation and improve collaborative practices between different disciplines. In order to examine these pedagogical practices, the literature review briefly describes some recent research on interdisciplinarity and processes of team formation. Interdisciplinary research requires students to quickly adjust to classmates with different backgrounds and begin to form shared meanings and patterns of work. In dealing with this non-traditional context, the role of instructors and their pedagogical techniques becomes crucial to helping students form and manage groups. In examining how the instructors in our case study structured the class to help students facilitate group building, the methods section briefly describes the pedagogical techniques that the faculty used. We also discuss the basic setting, instructor backgrounds, student backgrounds, environmental setting, and how data was collected. In proceeding with the results and discussion section, we address how the art and science of team building rests on the theoretical premise of promoting similarities in the group and preserving differences by allowing these units to self-manage their activities. We postulate that these interactions between students from different backgrounds allow for insights into how students are able to break down barriers between knowledge domains and innovate by building an interdisciplinary ethos. We then conclude with pedagogical observations that can be extracted from our study to other interdisciplinary classroom settings.

\section{Literature Review: Interdisciplinary Research and Formation of Groups}

\section{A. Interdisciplinary Teams in a Classroom Setting}

As engineering problems continue to include technical, social, and political aspects, research solutions are increasingly interdisciplinary. Traditional disciplinary boundaries and methodologies are no longer adequate to address problems rooted in complexity and diversity. Boundaries and borders have to be relaxed, if not suspended, to examine the complexities of problems found in nature and social settings. The division of people based on expertise has to be navigated and negotiated in order attend to problems, opportunities and solutions. The 
Committee on Facilitating Interdisciplinary Research points out that interdisciplinary research begins with the assumption of "the complexity of nature" 2 . It notes that disciplines like ecology have had to evolve to consider not only small scale problems, but large scale processes that impact the broader environment. This move toward interdisciplinary research is a result, according to the Committee, of "the inherent complexity of nature and society, the desire to explore problems and questions that are not confined to a single discipline, the need to solve societal problems, and the power of new technologies" 2 .

Pervasive computing design in particular requires interdisciplinary teams. This emerging design and research area, also known as "ubiquitous computing," focuses on seamless interactions between "smart" devices and users ${ }^{3,4}$. This focus represents a major cognitive shift for engineering faculty and students, as well as people from other disciplines working in the area. In pervasive computing applications, designers create interactions that are not linear (like, for example, traditional engineering design processes that result in a stand-alone product). Also, pervasive computing designs are not dependent on self-direction by the user (like Flash and web pages, for example). Rather, the product for designers employing computing as a material is actually the process of use - the space where a product fits seamlessly into a person's life. The user does not have to learn new software technology or hardware-more often the new technology is embedded into old technology. Thus, engineers are needed to design computer programming for the product. Industrial Designers are necessary for designing usable, appealing interfaces, which is now critical to a product's functionality. And, marketing experts are needed to create new niches in the market and to convince people that the smart products are worth their cost.

Furthermore, interdisciplinary collaboration is different from typical "divide-and-conquer" approaches that work with single discipline teams who share epistemologies. Research on interdisciplinarity as a skill or a professional characteristic defines it as the ability to be cognitively flexible and to learn from other disciplines in a process of integrative knowledge building ${ }^{5-7}$. Interdisciplinary teams must invest more time and effort into establishing foundations in which they are aware of the differing values and processes of other disciplines and are able to find ways to work adaptively with each other despite differences ${ }^{8}$.

That is, students with interdisciplinary competence understand the methods and knowledge base of other disciplines as well as their own field; they can integrate different knowledge systems and recognize the benefit of other approaches. Learning outcomes in interdisciplinary courses can include developed critical and analytical skills, enhanced ability to view complex problems from multiple perspectives, and increased ability to navigate this information age in ways that synthesize multiple sources of knowledge ${ }^{5}$.

Thus, the emerging research field faces several challenges: it must be interdisciplinary and able to work with other knowledge systems, and it must change its thinking about fundamental design processes. So, the next questions are, How do we do all of this faster? and, How do faculty, also functioning as an interdisciplinary team, facilitate these conceptual shifts in understanding?

To put this type of research into classroom practice, we argue that the concept of teams become a central unit of analysis. Cohen and Bailey ${ }^{9}$ point out that there are four different types of teams, 
which can be used in particular settings to accomplish specific objectives: work teams, parallel teams, project teams, and management teams. Although any of these teams can be interdisciplinary in nature, project teams are designed to quickly bring people together with different specialties in order to address complex problems. Project teams, according to Makin, Cohen, and Bikson, are temporary, formed to complete a non-repetitive task, and crossfunctional ${ }^{10}$. Reorganizing based on interdisciplinary needs is relied upon to foster creativity in an organizational setting. Free from the constraints of permanent work teams, these teams are constructed to be innovative and self-managing with little supervision from the outside.

\section{B. Team Formation}

We seek to examine how interdisciplinary project teams form in a classroom setting. What makes team forming in an interdisciplinary environment so complex is that it requires an extended amount of time to deal with differing disciplinary epistemologies; that is, disciplines differ in what is valued as knowledge, creativity and product. This challenge makes conflict more prevalent and the communication process more strenuous. Makin et al. argue that "diversity breeds conflict" 10 and Brown and Eisenhardt note that the "underlying premise is that communication among project team members and with outsiders stimulates the performance" ${ }^{11}$. These conflict and communication issues are difficult in a time-limited operation that requires quick results. In a classroom setting that is bound by either a semester- or year-long course, there is not much time to build relationships that allow people to work together with a cohesive approach, or "on the same page."

To overcome these challenges to group formation, faculty can use norms to help facilitate group formation. Norms often refer to general rules that are commonly accepted by a community. They prescribe what type of behavior is justifiable in a given context. The process of norming establishes standards that all members of a group can easily acknowledge. From a psychological perspective, Tuckman ${ }^{12}$ describes how norming is a critical element in group cohesion. He argues that small groups develop sequentially. They go through a process of orientation, conflict, cohesion, and performance. This process of forming, storming, norming, and performing tells the story of how small groups are able to unite and pursue a common goal. In particular, the storming and norming aspects are critical, especially in interdisciplinary groups such as in our case study, where individuals must value and learn from other's perspectives. Tuckman describes how, in the storming and norming process, groups are able to overcome internal conflict and form a tight cohesive unit. In fact, he compares this relationship to that of a family. A group unites to pursue a common goal. Relationships are marked by support, commonalties, and recognition of differences-again, a substantial challenge in groups with differing disciplinary perspectives.

However, Tuckman's sequential process of group formation is overly simplistic and unrealistically linear. Groups often do not go through such a linear and predictable process to form. Still, Tuckman was able to show how norming was critical in group formation. Scott ${ }^{13}$ sees the normative pillar of social institutions as critical in creating coordination and community in organizations. In particular, Scott argues that normative systems specify valid ends and legitimate means. Norms provide a general template for individuals to use as dependable signposts for forming and working in collaborations. Norms define valid and invalid ways of 
doing things in a particular community. Hence, norms are able to empower and constrain action. In our case study, instructors intentionally constructed a loose institutional structure in order to encourage interdisciplinarity as a learning outcome.

Like Tuckman, Gersick ${ }^{14,15}$ also argues that norms have the capacity to unite individuals in the pursuit of common ends, especially in the first phase of group development. However, Gersick reconceptualizes Tuckman's model using punctuated equilibrium theory to understand group dynamics. In particular, groups experience two types of phases: stasis and inertial movement. In the first phase, groups form and norm. During this phase, groups experience stasis and incremental change. There are few structural constraints and implementation of ideas does not occur. Most expectations are generated based on function of the task, the setting, and perceptions of other team members after the first meeting. In this particular study, we are focusing on how students can combine disciplinary perspectives and cohesively form in this first phase while simultaneously brainstorming ideas and forming project goals. Although the transition to implementation is important, we want to further explore the first phase of group development. Jarvenpaa, Shaw, Staples ${ }^{16}$ show how trust in situations with weak structure have a positive and helpful impact on group performance in the first phase. In order to form groups in time sensitive cases, faculty need to rely on creating a strong normative system to help students come together in a timely manner.

\section{Methods}

As the literature review demonstrates, existing scholarship on interdisciplinary design collaborations suggests a clear need for engineering educators to understand and teach transferable practices that students can bring to interdisciplinary design team environments. Shuman et al. raise concerns that many instructors put students into group learning environments without providing guidance ${ }^{17}$. Colbeck et al. similarly find that although group projects are quite common, instruction that helps students consciously learn about teaming is often absent ${ }^{18}$. The instructors' approach in this case study, although providing a very loose structure, nonetheless established an environment in which interdisciplinarity was highly valued and team formation occurred through a process of guided ideation and synergy that existed across individual project teams. Importantly, the case study is not intended as representative of all engineering students' prior knowledge and practices ${ }^{19}$; rather, in examining one group of students closely, it raises important research questions and provides the basis for further inquiry in this key area of design team practice and education.

\section{A. Setting and Participants}

To explore these issues of group formation in a classroom setting, this study observed an interdisciplinary class for Pervasive Computing Design that focused on smart dorm rooms. We looked at how students from a variety of backgrounds came to form and reform groups in a speedy and efficient manner. Twenty-one students enrolled in a semester-long class in the fall of 2008 that focused on using smart technologies to build dorm rooms for students with special needs. The course was not mandatory, though the students were in most cases able to use the course for either design credit or in place of a mandatory course. There were seven engineers, eight marketing students, and six industrial design students. The academic levels of these students ranged from sophomores to graduate students, but the majority of students were seniors. 
Three faculty members taught and oversaw the class whose backgrounds included engineering, marketing, and industrial design.

The class convened two times a week for 75 minutes in a classroom specifically designed for group collaboration. Groups were given the latitude and freedom to work without extensive faculty oversight or surveillance. The class did not have to share its room with any other classes on campus. They could enter the classroom anytime, put posters on the wall, rearrange seats, or use any of the white boards. Although the classroom had tables and chairs, it was not designed for classroom instruction. There was no linear or permanent structure of the classroom, which allowed for students to construct the space to their needs. The flow of the classroom was loose, unorganized, and unstructured. The white boards were on wheels, which allowed the students to freely move and rearrange their workspaces. Furthermore, the classroom also had a separate couch section, which allowed the students to sit and chat in an informal manner.

The course was run as a design studio with an open environment where students learn from each other in a dynamically developing systems structure. In this case study, the course took place in one semester devoted to problem definition, conceptual development, and initial feasibility studies and prototyping. The problem area of the course was introduced by bringing in domain experts from the university's Assistive Technologies Lab. These domain experts not only provided technical information, but they established the "higher-cause" that motivates student buy-in to the project. Whole group 'solution opportunity-seeking' immediately followed these presentations.

The presentation of brainstorm directions was followed by discussion and re-forming of teams based on interest and expertise. The teams proceeded to develop the projects through schematic sketches, computer models, and physical prototypes. Faculty were seeding entrepreneurial activities in this stage by providing access to tooling, components, additional faculty or industry expertise. Final presentations to the project's domain experts closed out the first semester, based on a final written design report, which included a marketing plan, an engineering feasibility study, and a designer's project book. Evaluation consisted of individual assignments spread throughout the semester, the final presentation, and the final project book.

In the future, the projects will be conducted over two semesters, with the second semester devoted to detailed design and implementation. The second semester will include regular planning sessions, whole group project updates and critiques, incorporating more domain experts, and encouraging an "anthropological" approach to learning about the context where the end product will be in use.

\section{B. Data Collection and Analysis}

To determine how the students and groups formed and developed, we asked for permission to observe them throughout the semester. All of the students and faculty signed an IRB permission form on the first day of class. They also agreed to do individual interviews and individual assessments throughout the semester. Additional methods of data collection included quantitative and qualitative data from questionnaires targeting the concepts of creativity, trust and interdisciplinarity. This paper focuses on qualitative data from observations and interviews, while additional data is reported in separate publications ${ }^{20,21}$. After the introduction and explanation of the research project, one member (and sometimes two members) of the research 
team consistently observed classroom instruction and group meetings as an objective outsider and all classroom discussions were audio recorded. The objective outsiders merely observed and took notes throughout classroom instruction and team meetings. Each week, the notes were typed, reviewed, and analyzed. They were also checked with the recording if needed. The class met 30 times throughout the semester. In addition to this, the research team also interviewed twelve of the students on two separate occasions. The first set of interviews occurred at the midway point and the second set occurred during the final week of class. Students were expected to answer a series of open-ended questions and fill out a questionnaire.

In examining the process of group formation through a process of norming and interaction, the authors observed group dynamics in the classroom setting. After close observation and receiving feedback from students and instructors, we extracted three categories of how groups are able to form in an effective and efficient manner. Once these classifications were selected, one author coded them and looked at class transcripts and interviews to determine what pedagogical practices were helpful in building coordination and communication among students. These selected categories were (1) desire to work in interdisciplinary groups, (2) manifestations of group cohesion, and (3) the balance between structure and openness. The desire to work in interdisciplinary groups reflected the promotion and applicability of each team's project in the classroom and work setting. Group cohesion was manifested by the ability of students to come together and produce ideas. Finally, openness was marked by a lack of rules and stringent requirements. Students were given the flexibility to organize and produce.

\section{Results and Discussion}

Question 1: What instructor strategies help to create an interdisciplinary environment that facilitates quick formation of cohesive teams?

The instructors used several strategies to build a supportive interdisciplinary environment, including (1) modeling interdisciplinarity by coalescing as faculty on shared goals, (2) encouraging both formal and informal processes to create relational space, and (3) giving ownership of physical and social space to the students.

In facilitating the building of smart dorms that would help students with special needs, the faculty agreed that it would require students to come together quickly, but in an integrated way. All three of the instructors spoke very clearly about this, with the Industrial Design professor being the most direct: "We are trying to figure out how to build teams more quickly." The first method the faculty relied on to create an interdisciplinary environment was norming the students to accept uncertainty and diversity in a classroom setting. The marketing professor stated, "Each of you started with a broad category and each of them still overlaps."

They imposed a strong ethos of the value of not only accepting but valuing the different disciplines of marketing, industrial design, and engineering. The very first day of class the faculty drew the basic concept of the course on a white board, explaining that they are trying to tear down walls (division of labor) in order to increase collaboration between different disciplines (marketing, design, and engineering). The marketing professor told the students, "We want to find synergy and move people around from group to group." 
The second day of class continued this norming process. The industrial design professor warned the students of typical difficulties of working with someone in a different academic field. He said, "One of things you are going to try to do is learn how to talk to people in other fields. We use the same words differently; it takes a while to get to know what each other is saying; you have to start somewhere and the basis is an inquisitive mind. Respect emerges from this. Spend some time working on this."

To build teams in this short-time span, the faculty encouraged both formal and informal processes to cultivate this process of overcoming interdisciplinary barriers. The formal interventions were undergirded by the faculty continuously reminding the class about the value and practicality of interdisciplinary project teams. For example, the instructors showed a professional video about the interdisciplinary process used by IDEO, a leading design firm where people from a cross section of different fields come together and increase creativity through a very informal process ${ }^{22}$. After watching the video, the engineering professor reinforced the norming process. He said, "We want you to be T-shape people. We want you to check your disciplines at the door. Later on, there will be a chance for you to contribute as a business student or engineering student. We are opportunity identifiers. We will build on the ideas of others." In this short statement, this faculty member formally combined the video that glorified the IDEO process with a lecture about becoming a T-shape person. A T-shape person is someone who is possesses the core strength of disciplinary expertise (the vertical axis of the ' $\mathrm{T}$ ') and also is able to see and work with a broad range of people and situations (the horizontal axis of the ' $T$ '). For the next five weeks (and for rest of the semester), the faculty continually spoke of value and necessity of being $\mathrm{T}$-shape people. This was a key metaphor that drove the norming process in a very formal way. The faculty also set up in-class team-building exercises where the students had to figure out together the solutions to a hypothetical situation and required students to keep project journals with guided prompts for reflecting on varying definitions of design and interdisciplinarity.

On the other hand, the instructors also encouraged an informal process of norming. The industrial design faculty noted, "I was having panic attacks because we just have 5 weeks to build teams. It takes a hunk of time just getting to know each other. We can do whatever we can to formally work together. Informal stuff is just as critical." The marketing professor said it another way: "We are creating an ambience." The instructors understood the inherent problems of getting students to gel in both a formal and informal process.

The instructors approached this issue by encouraging students to bond socially both in and out of class, and they backed this up by giving ownership of both physical and social space in the classroom to the students. With this encouragement, the students formed a Facebook group about smart dorm rooms, they hung pictures of themselves on the wall in class, brought donuts to share with everyone else, and even made nametags to wear. After a formal team-building exercise, students informally invited other students to go out. This was reinforced by the industrial design professor. He noted, "You can discuss anything. Two students need to get together to talk about basketball." The faculty expected students to talk about formal and informal things in class. 
Question 2: How do self-organized and self-managed teaming impact individuals' engagement in teaming and design?

In translating this rhetoric into practice, the faculty relied on the concept of self-organizing groups. Hard and static structures would limit the ability of students to gel. The faculty expected students to form and reform groups based on discipline and interest. These groups had to form quickly, generate ideas of how to build a smart dorm room, and then dissolve in order to refine and reform those ideas in other groups. At the same time, the groups had to overcome interdisciplinary barriers. One engineering student commented about the ease of working with other engineers, but the difficulty of working with marketing and design students. He noted in his interview, "Engineering groups can work a lot better. In those groups, I know my friends and I can hit them over the head if they are over the line. It is a lot easier because they understand the goals and concepts. We all know that these concepts work. In one of my classes, everyone knows what we are talking about. Marketing has no clue of what we are talking about." Despite these challenges, the faculty were able weave the benefits of an interdisciplinary ethos into the class. The same engineering student said, "The teams are very creative and pleasant. It does support creativity. I have not done this before and I want to find a job like this." A marketing student also commented about group interaction and formation in an interdisciplinary environment. She noted, "It is not like we are all similar. We are very different. It works together in good ways. We complete each other in good ways."

Overall, forming happened in just over six weeks via five distinct stages that were initiated by both instructors and students. By the end of the last stage, students were settled in permanent interdisciplinary teams, each with a coherent goal that would contribute a component to the planned smart dorm room. The only rule these groups had to follow was that they had to have a member of each discipline in them. Groups with just engineering or marketing or design students were not allowed. The self-organized forming took place through the following stages:

Stage 1: To generate ideas, the faculty created a loose brainstorming session where students pitched their ideas of what a smart dorm room could look like. Everyone was expected to follow the rules of brainstorming: freely participate, but do not criticize. The marketing professor encouraged students to drop disciplinary expertise at this early stage: "Don't think about making a better tooth brush for someone who has arthritis; think about someone looking at the mirror, smiling, and having their teeth cleaned. Think about something beyond the discipline." After the session ended, the industrial design professor commented, "If I had done this by myself, I would not have come up with this list."

Stage 2: With vague and broad ideas, the faculty divided the students into five cross sectional teams. Although the first group did not randomly form, they were expected to use their interdisciplinarity to refine and expand on the class's ideas. For the next two weeks, each group worked on developing concepts in a series of brainstorming activities without extensive faculty intervention. In handling this loose structure, one industrial design student noted, "They (professors) lead us, but not direct us. I think everyone is positive. Everyone is open to new ideas and no one is shutting down ideas. That helps creativity." In combining the formal and informal, one group met at a restaurant on campus to develop ideas. A marketing student from that class observed, "We came up with the bracelet idea in the beginning. We would go at lunch and shoot 
the breeze at West End Market. We started throwing out crazy ideas. An industrial design student was the one who thought of carrying a portable device that you could carry around with you. We started to come up with ridiculous functions for it and that is how the thing got started." This group followed the norming process that the faculty had suggested: use informal processes to innovate and facilitate group thinking.

Stage 3: After two weeks, the groups came back together to show what they developed. The common thread between the ideas was interconnectivity and communication. Due to the massive overlap of ideas, the industrial design faculty member mused about whether they could do two things at once.

Stage 4: An engineering student stepped forward and suggested that they split into two groups, one that would focus on ideas and the other to focus on products. Each student chose which group they would belong to and worked to further refine previous ideas. The engineering faculty member told the students, "We have reached a point in the semester where we [the instructors] shouldn't need to talk; you should be taking it over." With the move toward self-organizing teams, the faculty began to recede from group discussion and the students assumed more control. Although the faculty took less control over the situation, they provided a loose structure that allowed these groups to be creative, but work within limits. One marketing student described the role of the faculty. She observed, "They direct us. I was nervous in the first couple of classes because they told us we are not going to tell you what to make and you will figure it out on your own. I think they have led us in good directions. If they see anyone going in a wrong direction, they take a powerful role. They keep us on task."

However, the two larger groups failed to gel and produce new ideas. The teams (about 10 members each) were too large for students to arrange a time where they could meet out of class. For a week, they discussed concepts in class and out of class, but could not come up with any cohesive ideas. They relied on Blackboard chat rooms, instant messaging, and email to talk about and refine ideas, which failed. Posting and emailing was too linear and artificial. One industrial design student observed, "It seemed static. With smaller groups, you could get feedback. There was some dialogue." Another industrial design student also commented about the lack of community and exchange of ideas. He noted, "In person, it's a lot easier to play off each other and build off of ideas. You can't interpret emotions or connotations of words. It is stagnant. It is hard to build something as a part of a community."

Stage 5: Students demanded that groups be destroyed and reformed into smaller units; the large groups did not allow for the same creative process and group formation. To ensure this, an industrial design student announced, "Pick your group. Let's use stations in the room and people go there." They decided that five groups should be created in order to address the five big issues of dorm life. Each student decided which group they would join. Within these groups, the reliance on chat boards and IM chatting ended. Students met in person inside and outside of class. In developing these final project teams, one student observed how the three disciplines worked together in a cohesive manner. She said, "Another marketing student and me are talking about who it is going to benefit, what is the best way to make it happen, is it going to be expensive, are people going to want it, the marketable aspect to the product. The industrial designer comes in with the drawing. The engineer is always analytical with things and always 
says whether it will be feasible or not." Another industrial design student reinforced this sentiment. He said, "Different perspectives, different way of seeing things, different disciplines; everyone brings an ingredient to the mix." The group cohesion was marked by differences, but a common framework of understanding how the different parts work together. He continued, "You can't do it on your own. I heard something yesterday about designing something. It is better to have a group dynamic than having a single genius in the room. You are not going to get it done without a group working on different parts."

\section{Conclusion}

This case study has provided insights on how instructors can help students learn hands-on teambuilding in a loosely structured, interdisciplinary environment. Finding "middle ground" between top-down structuring and the common practice of providing no guidance is important as engineering students learn to design in teams. Pervasive computing, in particular, requires interdisciplinary approaches and challenges students with its new perspective on the end product as a process.

The students in this study succeeded in crossing disciplinary boundaries to propose and develop innovative designs. Their products were design proposals that could enter the build stage in a subsequent design semester. The teaming skills they learned were observed by researchers, instructors and themselves. Several patterns emerged from this collection of data that is supported by the literature and thus lends credence to this pedagogical approach that encourages self-organized and self-managed teaming in senior design courses.

- Combining the teaming stage of forming and the design stage of ideation helped students organize and choose teams. The forming and dismantling of teams, and migration from team to team, enabled more solid final project teams. Additionally, the movement in this early stage created better relational space within teams and better synergy across teams. This "cross-fertilization" between teams should continue throughout the project.

- Teaching interdisciplinarity helped students not only accept students from other disciplines, it also resulted in genuine respect and valuing others' perspectives. This respect for both discipline and person is necessary for knowledge building to take place-for true interdisciplinary experiences in which team members learn and benefit from one another as they create solutions that would not otherwise have been thought of. Furthermore, instructors established this norm by emphasizing that different terminologies present a challenge that points to something deeper-the way different disciplines think and value knowledge.

- Finally, instructors granted autonomy to students, which resulted in increased engagement and responsibility for both the projects and the functioning of the teams. Given this freedom, along with a flexible physical classroom environment that the teams could shape themselves, students constructed both professional and social interactions that allowed them to define their own roles and thereby play a significant part in the design process. 


\section{Works Cited}

${ }^{1}$ G. Madey, V. Freeh, and R. Tynan, "The Open Source Software Development Phenomenon: An Analysis Based on Social Network Theory," pp. 1806-1812, 2002.

${ }^{2}$ Committee on Facilitating Interdisciplinary Research, "Facilitating Interdisciplinary Research," National Academies Press, Washington, 2004.

${ }^{3}$ M. Satyanarayanan, "Pervasive computing: Vision and challenges," IEEE Personal Communications, 8[4] 10-17 (2001).

${ }^{4}$ M. Weiser, "The Computer for the 21st Century," Scientific American, 265[3] 94-104 (1991).

${ }^{5}$ L.R. Lattuca, L.J. Voigt, and K.Q. Fath, "Does Interdisciplinarity Promote Learning? Theoretical Support and Researchable Questions," The Review of Higher Education, 28[1] 23-48 (2004).

${ }^{6}$ V.B. Mansilla, "Assessing Student Work at Disciplinary Crossroads," Change 37[1] 19 (2005).

${ }^{7}$ V.B. Mansilla and E.D. Duraising, "Targeted Assessment of Students' Interdisciplinary Work: An Empirically Grounded Framework Proposed," Journal of Higher Education, 78[2] 215-23 (2007).

${ }^{8}$ M. Borrego and L. Newswander, "Characteristics of Successful Cross-Disciplinary Engineering Education Collaborations," Journal of Engineering Education, 97[2] 123-34 (2007).

${ }^{9}$ S.G. Cohen and D.E. Bailey, "What Makes Teams Works: Group Effectiveness Research from the Shop Floor to the Executive Suite," Journal of Management, 23[3] 239-290 (1997).

${ }^{10}$ D. Makin, S. Cohen, and T. Bikson, "Teams and Technology: Fulfilling the Promise of the New Organization," Harvard Business School Press, Boston, 1996.

${ }^{11}$ S. Brown and K. Eisenhardt, "Product Development: Past Research, Present Findings, and Future Directions," Academy of Management Review, 20[2] 343-378 (1995).

${ }^{12}$ B.W. Tuckman, "Developmental sequence in small groups," Group Facilitation, 3 66-81 (2001).

${ }^{13}$ R.W. Scott, "Institutions and Organizations," Sage Publication, Thousand Oaks, CA, 2001.

${ }^{14}$ C.J.G. Gersick, "Time and Transition in Work Teams: Toward a New Model of Group Development," The Academy of Management Journal, 31[1] 9-41 (1988).

${ }^{15}$ C.J.G. Gersick, "Marking Time: Predictable Transitions in task groups," The Academy of Management Journal, 32[2] 274-309 (1989).

${ }^{16}$ S.L. Jarvenpaa, T.R. Shaw, and D.S. Staples, "Toward Contextualized Theories of Trust: The Role of Trust in Global Virtual," Information Systems Research, 15[3] 250-267 (2004).

${ }^{17}$ L.J. Shuman, M. Besterfield-Sacre, and J. McGourty, "The ABET 'Professional Skills' - Can They Be Taught? Can They Be Assessed?," Journal of Engineering Education, 94[1] 41-56 (2005).

${ }^{18}$ C.L. Colbeck, S.E. Campbell, and S.A. Bjorklund, "Grouping in the dark: What college students learn from group projects," Journal of Higher Education, 71 60-83 (2000).

${ }^{19}$ R.K. Yin, "Case Study Research: Design and Methods," Sage Publications, Thousand Oaks, 2003.

${ }^{20} \mathrm{~K}$. Kim and L.D. McNair, "Flexible learning environments to improve interdisciplinary creativity and team interactions," San Antonio, TX, 2009.

${ }^{21}$ K. Kim and L.D. McNair, "Creativity of interdisciplinary engineering design teams: An in-depth look beyond brainstorming," in 53rd Human Factors and Ergonomics Conference. Edited, San Antonio, TX, 2009, submitted.

${ }^{22}$ IDEO, 2009. 